\title{
High-midlatitude ionosphere response to major stratospheric warming
}

\author{
Boris G Shpynev ${ }^{1 *}$, Vladimir I Kurkin, Konstantin G Ratovsky', Marina A Chernigovskaya ${ }^{1}$, Anastasiya Yu Belinskaya²,
} Svetlana A Grigorieva ${ }^{3}$, Alexander E Stepanov ${ }^{4}$, Vasily V Bychkov ${ }^{5}$, Dora Pancheva ${ }^{6}$ and Plamen Mukhtarov ${ }^{6}$

\begin{abstract}
This study investigates the impact of dynamical processes in the neutral atmosphere on the high-midlatitude ionosphere during two sudden stratospheric warming (SSW) events. For this purpose, the reanalysis meteorological data of the National Centers for Environmental Prediction/National Center for Atmospheric Research (NCEP/NCAR) and UK Met Office (UKMO) were used in addition to that from the high-midlatitude chain of Russian ionosonde stations. The results show that the ionospheric response to the SSW events at high-midlatitudes depends on the position of the ionosonde stations relative to the stratospheric circulation pattern. Two well-pronounced effects were detected in this study. The first effect, observed in January 2009, was a negative effect in critical frequency $\left(f_{0} F 2\right)$ and a positive effect in $F 2$ layer maximum $\left(h_{m} F 2\right)$ above the border of a stratospheric cyclone and an anticyclone with northward flow direction. During a 6-day period, the ionosphere exhibited a sharply inhomogeneous longitudinal structure when ionosondes, displaced at a longitude of approximately $20^{\circ}$, showed differences of approximately $1 \mathrm{MHz}$ in $\mathrm{f}_{\mathrm{o}} \mathrm{F} 2$ and more than $50 \mathrm{~km}$ in $\mathrm{h}_{\mathrm{m}} \mathrm{F} 2$. The second feature, which was clearly observed in January 2013, implied a positive effect in $\mathrm{f}_{\mathrm{o}} \mathrm{F} 2$ up to approximately $2.5 \mathrm{MHz}$ and a negative effect in $\mathrm{h}_{\mathrm{m}} \mathrm{F} 2$ at approximately $10 \mathrm{~km}$ above the center of the stratospheric cyclone. We conclude that these effects were caused by upward transport of molecular gas to the lower thermosphere for the first case and a pulldown forcing of molecular species above the low-pressure zone inside the cyclone for the second case. Changes in the $\mathrm{O}^{+} / \mathrm{N}_{2}$ ratio in the lower thermosphere altered the $\mathrm{O}^{+}$recombination rate and the corresponding variations of ionosphere parameters.
\end{abstract}

Keywords: Sudden stratospheric warming; Atmosphere-ionosphere coupling; Ground-based ionosonde measurements

\section{Findings Introduction}

The middle atmosphere dynamical regime in winter is dominated by a large-scale dynamical structure known as the circumpolar vortex (CPV). This structure is a region of high atmospheric vorticity that forms with the establishment of the winter stratospheric polar jet. The physical mechanisms responsible for CPV acceleration are cooling and lowering of the atmospheric gas during polar nights and transformation of the gas gravity potential to kinetic energy of the vortex. The CPV is unstable due to planetary wave (PW) activity, and the interaction of PWs with the CPV zonal flow can alter the middle atmosphere dynamics dramatically, which occurs in sudden stratospheric warming (SSW) events. Modeling

\footnotetext{
* Correspondence: shpynev@iszf.irk.ru

${ }^{1}$ Institute of Solar-Terrestrial Physics SB RAS, Irkutsk, Russia

Full list of author information is available at the end of the article
}

shows that this interaction changes the structure of the CPV and induces downward circulation in the stratosphere, which caused adiabatic heating and upward circulation in the mesosphere, in turn causing adiabatic cooling (Liu and Roble 2002).

Recent studies have clearly identified large perturbations of the ionosphere, particularly in the ion drift measured at Jicamarca, and total electron content at low latitudes during SSW events (Chau et al. 2009; Goncharenko et al. 2010a, b). The global spatial (latitude and altitude) structure of the mean ionospheric response to SSWs was investigated for the first time by Pancheva and Mukhtarov (2011), who studied SSW events during the winters of 2007 to 2008 and 2008 to 2009. To elucidate the effects of SSWs on the ionosphere, FORMOSAT-3/COSMIC satellite $f_{\mathrm{o}} \mathrm{F} 2$ and $\mathrm{h}_{\mathrm{m}} \mathrm{F} 2$ data in addition to electron density data at fixed altitudes have been analyzed, the results of which indicated negative responses to the 


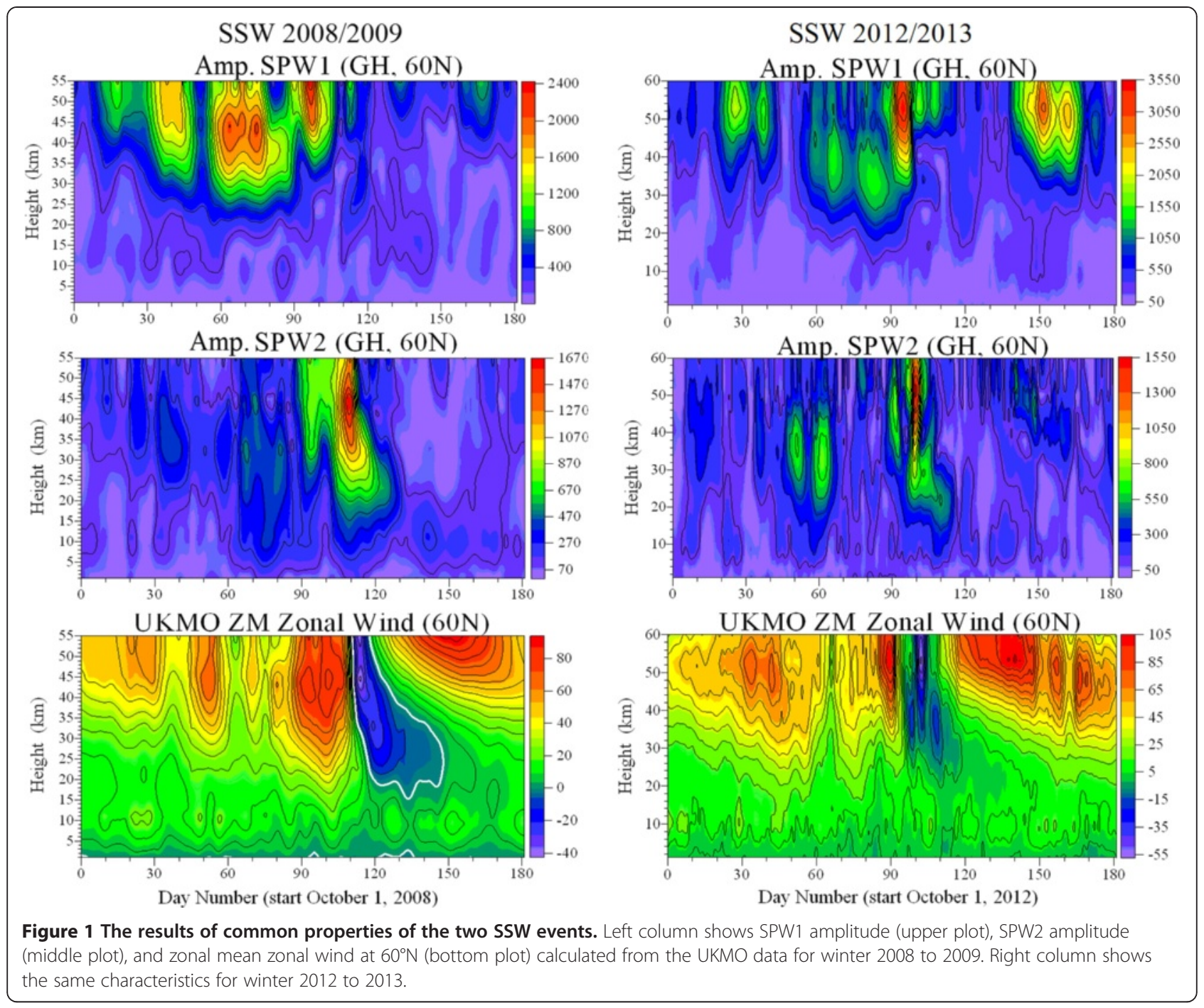

SSW temperature pulses at high latitudes. Similar responses were found for diurnal variability of the COSMIC electron density. These effects were confined to low and middle latitudes.

These ionospheric observational results were facilitated by the appearance of strong SSW events in 2008 and particularly those in January 2009 in addition to very low levels of solar and geomagnetic activity. Such conditions are ideal for studying vertical coupling between different atmospheric regions, allowing for unambiguous determination of the ionospheric effects related to forcing from below. Because the SSWs are related to rapid enhancement of stationary PWs (SPWs), tides, and circulation changes, the observed ionospheric variability could be related to these dynamical processes.

The basic objective of this paper is to trace out the coupling between stratospheric dynamics and ionosphere response at high midlatitudes during two major SSW events occurring in January 2009 and December 2012 to
January 2013. The present study uses the ground-based high-midlatitude chain of Russian ionosonde data, which enables investigation of the ionospheric response just above the CPV main stream with a longitudinal resolution of approximately $20^{\circ}$.

For analysis of the stratosphere dynamics, we used the database of the UK Met Office (UKMO) and reanalysis data of the National Centers for Environmental Prediction/ National Center for Atmospheric Research (NCEP/NCAR; Saha et al. 2013). The ground-based ionospheric observations were obtained by Russian ionosonde stations in Yekaterinburg, Novosibirsk, Irkutsk, Norilsk, Yakutsk, and Paratunka.

\section{Stratosphere dynamics}

The UKMO dataset was used to examine the features of the anomalies in the winter troposphere-stratosphere of the Northern Hemisphere. This dataset is the result of assimilation of in situ and remotely sensed measurements 


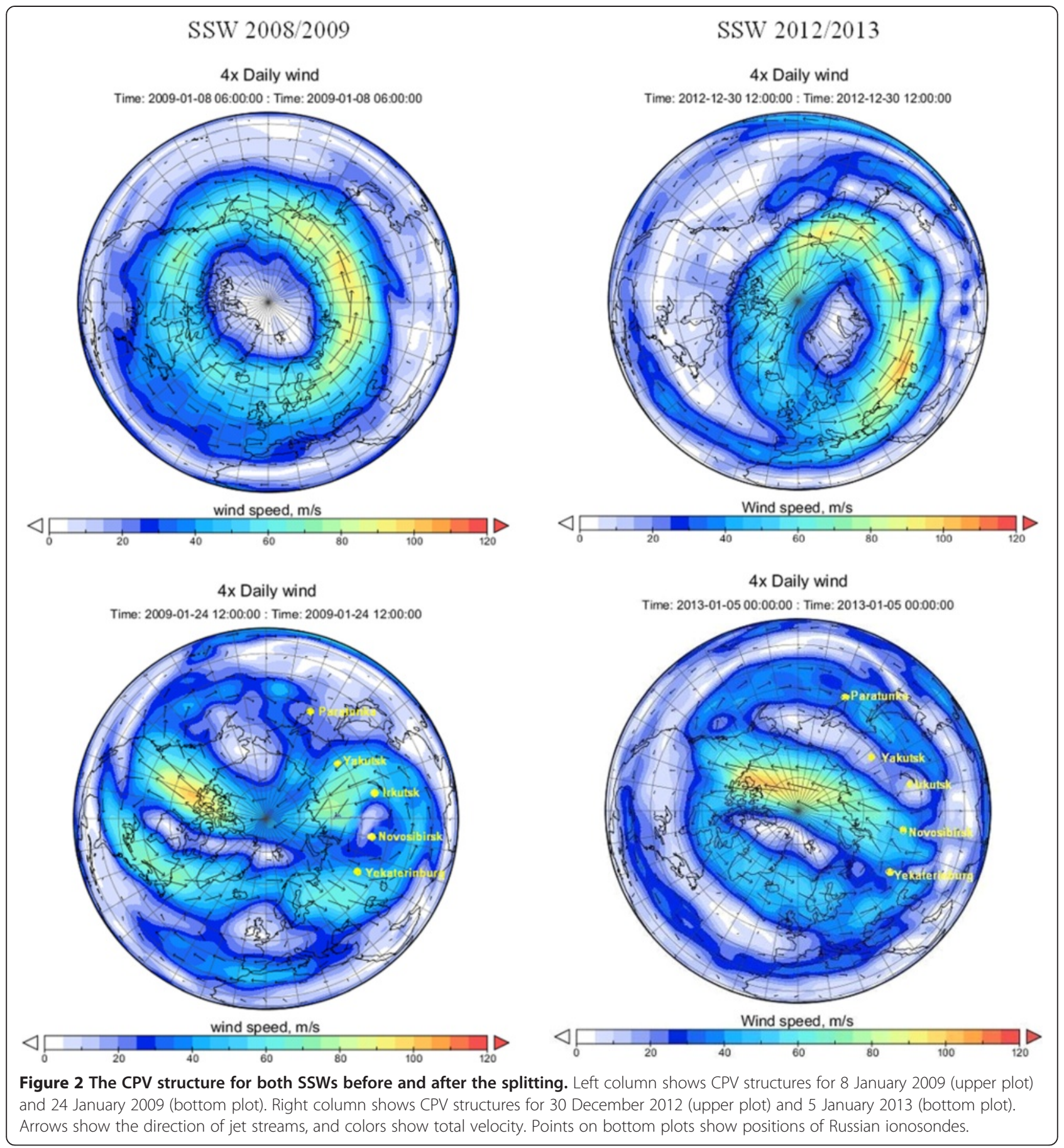

into a numerical forecast model of the stratosphere and troposphere. A description of the 3D-variational system was described by Swinbank and Ortland (2003). The outputs of the assimilation are global meteorological fields of daily temperature, geopotential height, and wind components at pressure levels from the surface up to $0.1 \mathrm{hPa}$. The daily data fields have global coverage with $2.5^{\circ}$ and $3.75^{\circ}$ steps in latitude and longitude, respectively. We used UKMO data because they effectively represent the global daily features of stratospheric dynamics. Moreover, these data were used for calculating the amplitudes and phases of SPWs with zonal wavenumbers 1 and 2, i.e., SPW1 and SPW2. To investigate the development of the SPWs, we used the UKMO geopotential height data. We defined the amplitude and phases of SPW1 and SPW2 by using a least squares best fit approach applied in a 3-day window that moved through the time series with steps of 1 day. This algorithm was developed in a previous 


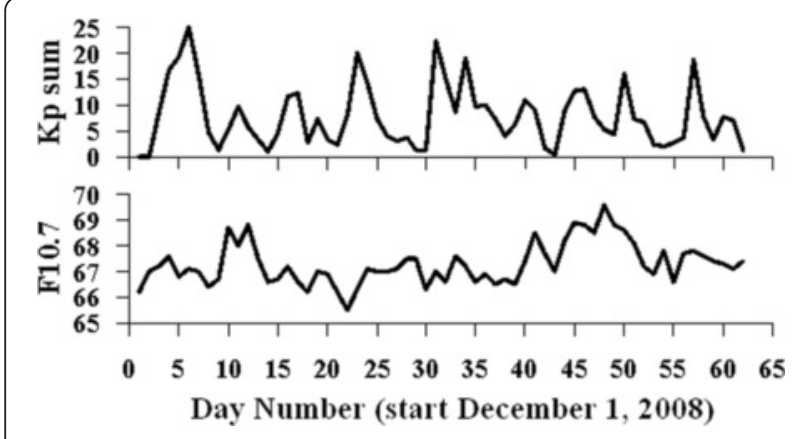

Figure 3 Geomagnetic and solar activity variations for SSW 2008 to 2009.

research by Pancheva and Mukhtarov (2011); its results were used as a time-marker of stratosphere warming development.

To analyze the common properties of the two SSW events considered in this study, we present the results in two columns in Figure 1 in which the left and right represent winters of 2008 to 2009 and 2012 to 2013, respectively. Upper and middle plots display the amplitudes of SPW1 and SPW2 in meters, respectively; bottom plots show the zonal mean zonal wind at $60^{\circ} \mathrm{N}$.

The development of both SSWs includes two phases. The first is an increase in SPW1 before events, which indicates a shift of circumpolar vortex from the pole. The second is an increase in SPW2, indicating a vortex division on couples of cyclones and anticyclones that are persistent for 6 to 10 days before weakening. The end of the SSW event is marked by an abrupt decrease in SPW 2. The reverse of zonal wind coincides with the increase in SPW2.

The events considered in this study differ by absolute values of parameters, which can be estimated from the color scales to the right of the plots in Figure 1. In the winter 2008 to 2009, the absolute values of SPW1 and zonal wind before the event were lower but existed longer. In the winter 2012 to 2013, these values were higher and shorter. The amplitude of SPW2 was higher in the winter 2008 to 2009 and lasted longer.

To illustrate the circulation structures in the stratosphere, we used NCEP/NCAR reanalysis data for horizontal wind. In principal, NCEP/NCAR and UKMO data are equivalent; we used NCEP/NCAR data here only because of the availability of the plotting program, which was previously adopted for this format.

Figure 2 shows the CPV structure for both SSWs before and after the splitting derived from the NCEP/ NCAR reanalysis data. The left column presents these structures for 8 January 2009 (upper plot) and 24 January 2009 (bottom plot). The right column shows CPV structures for 30 December 2012 (upper plot) and 5 January

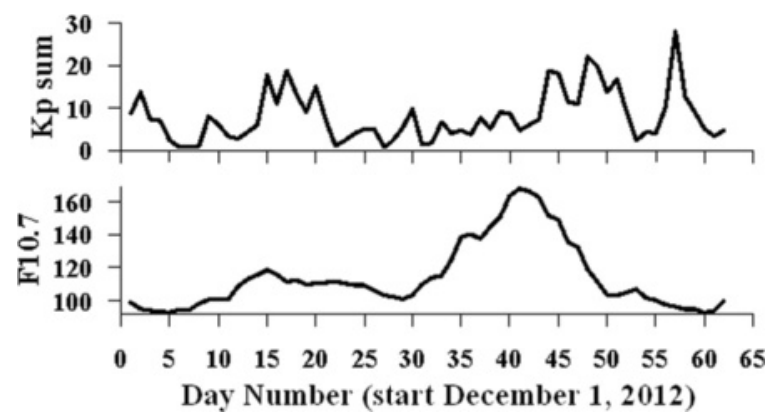

Figure 4 Geomagnetic and solar activity variations for SSW 2012 to 2013.

2013 (bottom plot). Arrows show the jet stream direction, and colors indicate total velocity. It is evident that the jet streams in both events had abrupt borders, and the wind structure after CPV splitting was inhomogeneous along the latitudes. The positions of Russian ionosondes, indicated on the bottom maps, were situated under different zones of stratospheric circulation.

\section{Use of Russian ionosondes chain for SSW studies}

To investigate the ionospheric response to SSW events at high-middle and high latitudes, we used data from the chain of Russian ionosonde stations usually situated under the CPV jet stream. We considered the temporal variability of the following main ionospheric parameters: critical frequency of the F2 layer $\left(f_{o} F 2\right)$ and the F2 layer maximum height $\left(\mathrm{h}_{\mathrm{m}} \mathrm{F} 2\right)$ measured by ionosonde stations in Yekaterinburg $\left(56.5^{\circ} \mathrm{N}, 60^{\circ} \mathrm{E}\right)$, Novosibirsk $\left(54.6^{\circ} \mathrm{N}, 83.2^{\circ} \mathrm{E}\right)$, Norilsk $\left(69^{\circ} \mathrm{N}, 88^{\circ} \mathrm{E}\right)$, Irkutsk $\left(52^{\circ} \mathrm{N}\right.$, $\left.104^{\circ} \mathrm{E}\right)$, Yakutsk $\left(62^{\circ} \mathrm{N}, 129.7^{\circ} \mathrm{E}\right)$, and Paratunka $\left(53^{\circ} \mathrm{N}\right.$, $\left.158^{\circ} \mathrm{E}\right)$. The longitudinal coverage of this chain is about $100^{\circ}$. For each SSW event described in this paper, we investigated the ionospheric response over different zones of stratospheric circulation. The longitudinal resolution of the ionosonde chain was about $20^{\circ}$, which is better than resolution of the COSMIC data on these latitudes used earlier for analyses of ionospheric response to SSW events (Pancheva and Mukhtarov 2011).

Chau et al. (2009) determined that the ionospheric response to SSWs is caused mainly by variability of the vertical plasma drifts due to the disturbed wind system. Together with influence from the upper atmosphere, the wind system in the lower thermosphere is shaped largely by tides forced from below. The ionospheric response can be connected with enhancement of tides during the SSWs, which leads to changes in the diurnal variability of the ionospheric parameters. Hence, we selected average characteristics of the ionosphere that do not depend on the short time scale irregularities presented in the winter ionosphere. 


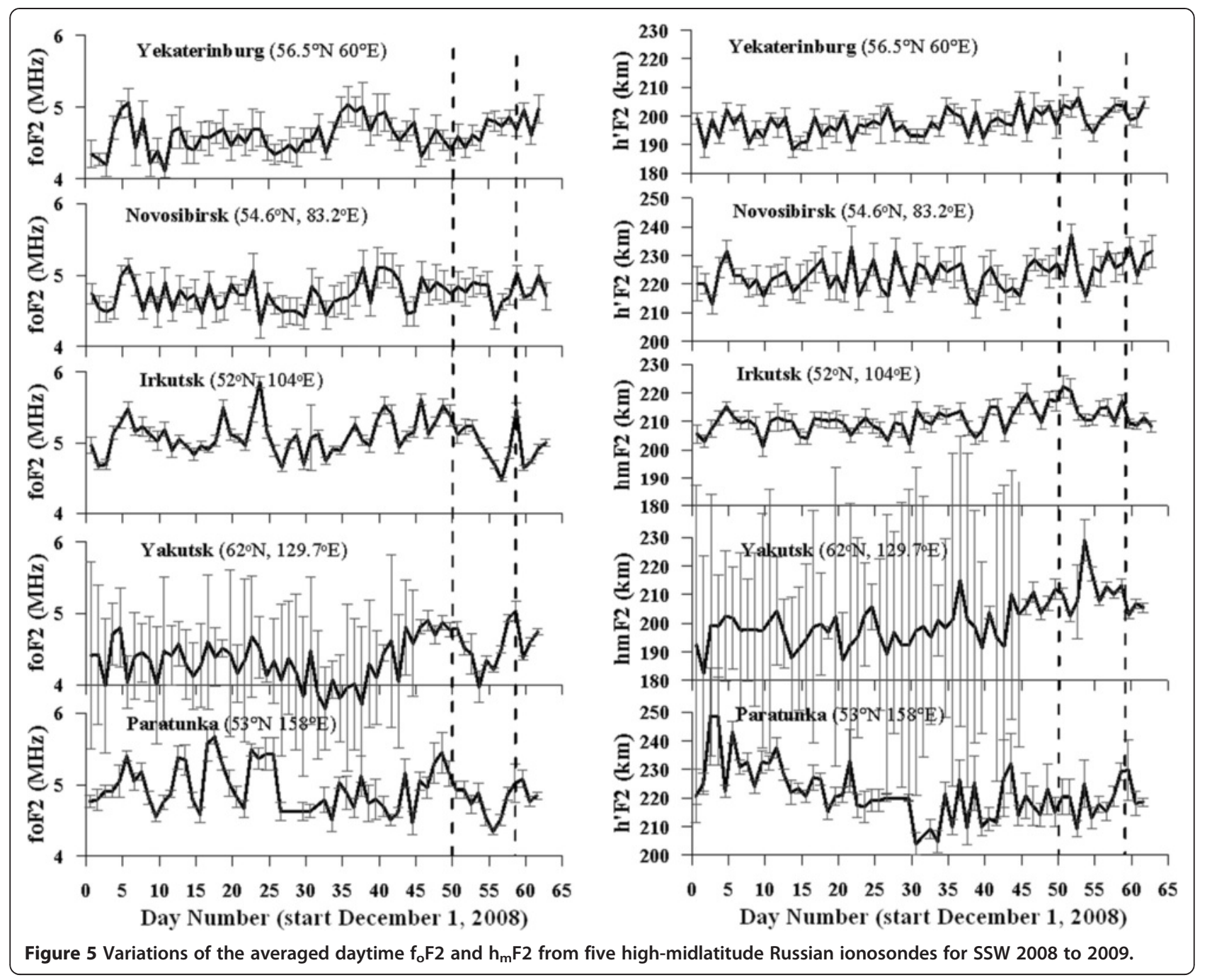

To investigate the day-to-day variability of the ionosphere at different geographical points, we averaged the $\mathrm{f}_{\mathrm{o}} \mathrm{F} 2$ and $h_{m} F 2$ data over 6-h intervals in the vicinity of local noon and local midnight at each site. The typical time resolution of the ionosondes is $15 \mathrm{~min}$; thus, 24 data points during the day and night were averaged. Poor data quality resulted in the absence of $3 \%$ to $30 \%$ of data at different sites. The standard deviation of the plots presented below characterizes the variability of parameters in the considered time intervals. For both events presented in this study, we considered ionosonde data for a time interval of 1 December to 31 January. Data from an auroral ionosonde in Norilsk were used for control of geomagnetic activity.

Observatories in Irkutsk, Yakutsk, and Norilsk are equipped with modern DPS-4 ionosondes, and their software can provide the actual height of maximum $h_{m} F 2$. Observatories in Yekaterinburg, Novosibirsk, and Paratunka use old-generation ionosondes; this equipment in standard mode provides the virtual height of only the F2 layer (i.e., h'F2) determined from ionograms. This difference is not critical for the purpose of the present study because we focus on the variations of these parameters. However, the absolute values of h'F2 on plots may differ from those of $h_{m} F 2$. We used $h_{m} F 2$, implying h'F2 for old-generation equipment.

During both SSW events, the auroral ionosonde in Norilsk did not show blackout ionograms in the daytime that occur during geomagnetic disturbances. Therefore, we concluded that the geomagnetic activity could be considered as undisturbed. Figures 3 and 4 display geomagnetic and solar activity variations for SSW 2008 to 2009 and SSW 2012 to 2013, respectively. The upper and bottom plots indicate a summary of $\mathrm{Kp}$ and F10.7 indices, respectively.

lonosphere dynamics during the SSW 2008 to 2009 event The SSW in December 2008 to January 2009 developed during very low solar and geomagnetic activity, which provided the best conditions for analysis of atmosphere- 


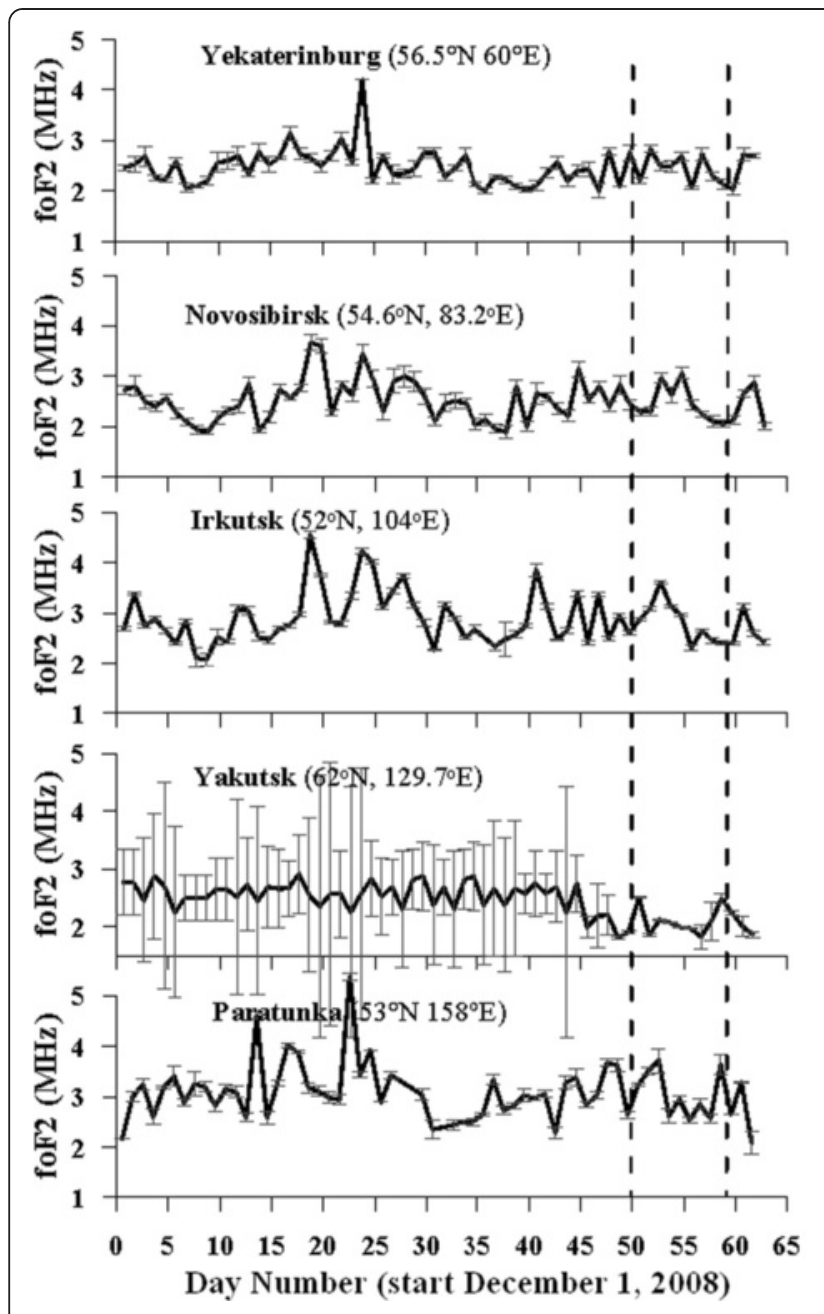

Figure 6 Same as Figure 5 but for averaged nighttime variations.

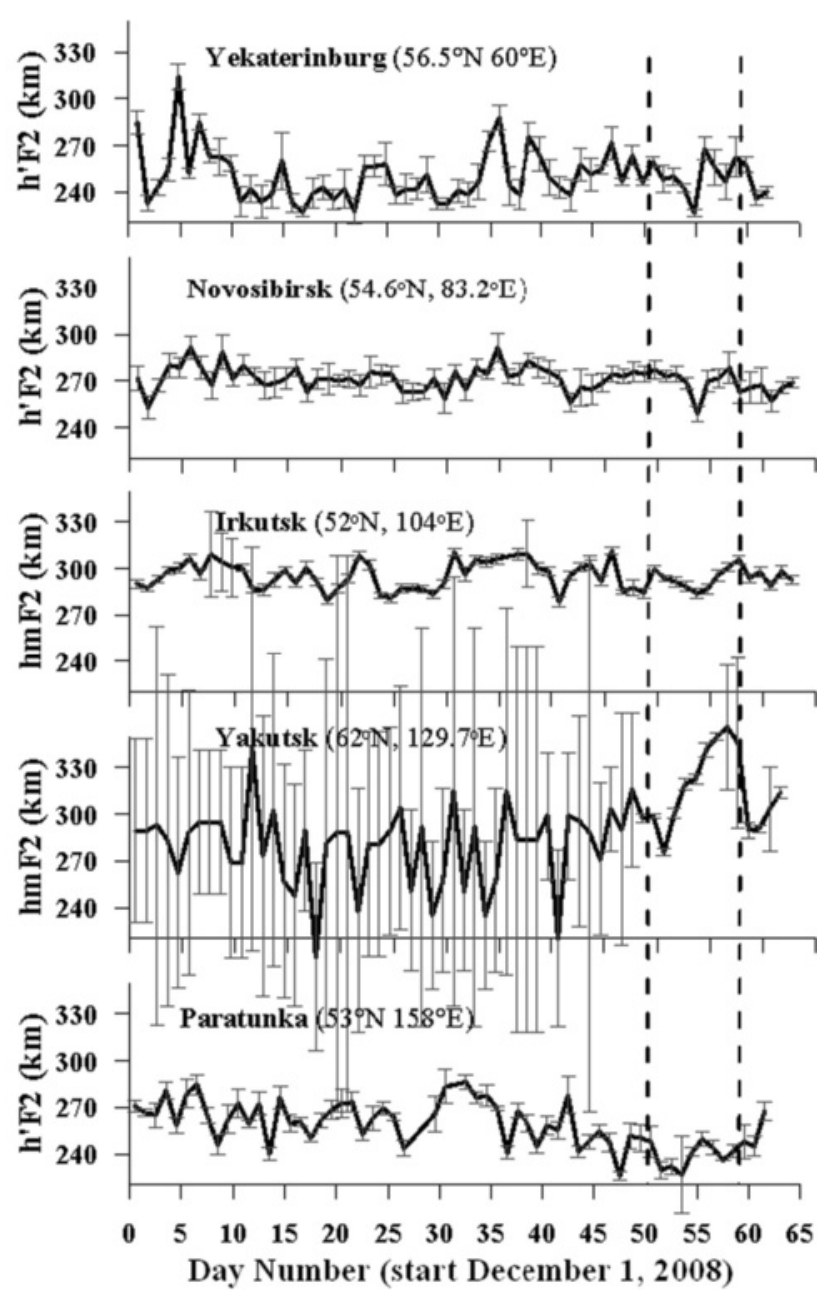

ionosphere coupling. As shown in Figure 3, the geomagnetic activity during this event was quiet. The summary $\mathrm{Kp}$ did not exceed 25, and the solar activity index F10.7 was less than 70 .

Figure 5 shows variations of the averaged daytime $\mathrm{f}_{\mathrm{o}} \mathrm{F} 2$ and $h_{\mathrm{m}} \mathrm{F} 2$ from five high-midlatitude Russian ionosondes for SSW 2008 to 2009. Placed on plot in accordance with their longitudes, these ionosondes include Yekaterinburg, Novosibirsk, Irkutsk, Yakutsk, and Paratunka; their positions are also shown in Figure 2. Vertical dashed lines show the time interval in which the CPV shifted from the pole, divided in pairs, and decayed. Figure 6 shows the same type of variations of $\mathrm{f}_{\mathrm{o}} \mathrm{F} 2$ and $\mathrm{h}_{\mathrm{m}} \mathrm{F} 2$ at nighttime. As shown in these figures, even the averaged daytime and nighttime ionospheric parameters show significant day-to-day variations due to tidal activity and geomagnetic variations. We averaged the ionospheric $\mathrm{f}_{\mathrm{o}} \mathrm{F} 2$ and $\mathrm{h}_{\mathrm{m}} \mathrm{F} 2$ parameters around noon and midnight local time for each site; we suggest that the tidal and geomagnetic variations must be approximately identical for every site in the chain. Hence, for investigating the SSW-induced variations, we focused on dynamics that differ among site. Moreover, we determined that 6-h averaging significantly reduces the influence of gravity waves with periods of 0.5 to $2 \mathrm{~h}$.

Variations of $\mathrm{f}_{\mathrm{o}} \mathrm{F} 2$ at daytime (Figure 5) demonstrate obvious longitudinal difference when eastern stations of Paratunka and Yakutsk show negative variations with minimums near day 55 (24 January). In Yekaterinburg, Novosibirsk, and Irkutsk, positive response occurred before day 55 , and the negative effect occurred in days 55 to 60 . The ionosonde in Yakutsk also showed an increase in $h_{m} F 2$ in the main phase of the event. A problem with the DPS-4 antenna in Yakutsk before 15 January resulted in the availability of only a few data points in day and night, which is shown by large error bars in the plots.

Nighttime variations (Figure 6) show slight increases in $\mathrm{f}_{\mathrm{o}} \mathrm{F} 2$ in Novosibirsk and Irkutsk and decreases in Yakutsk and Paratunka. The differences in nighttime $h_{m} F 2$ variations were more pronounced with negative response in Yekaterinburg, Novosibirsk, and Irkutsk and high 

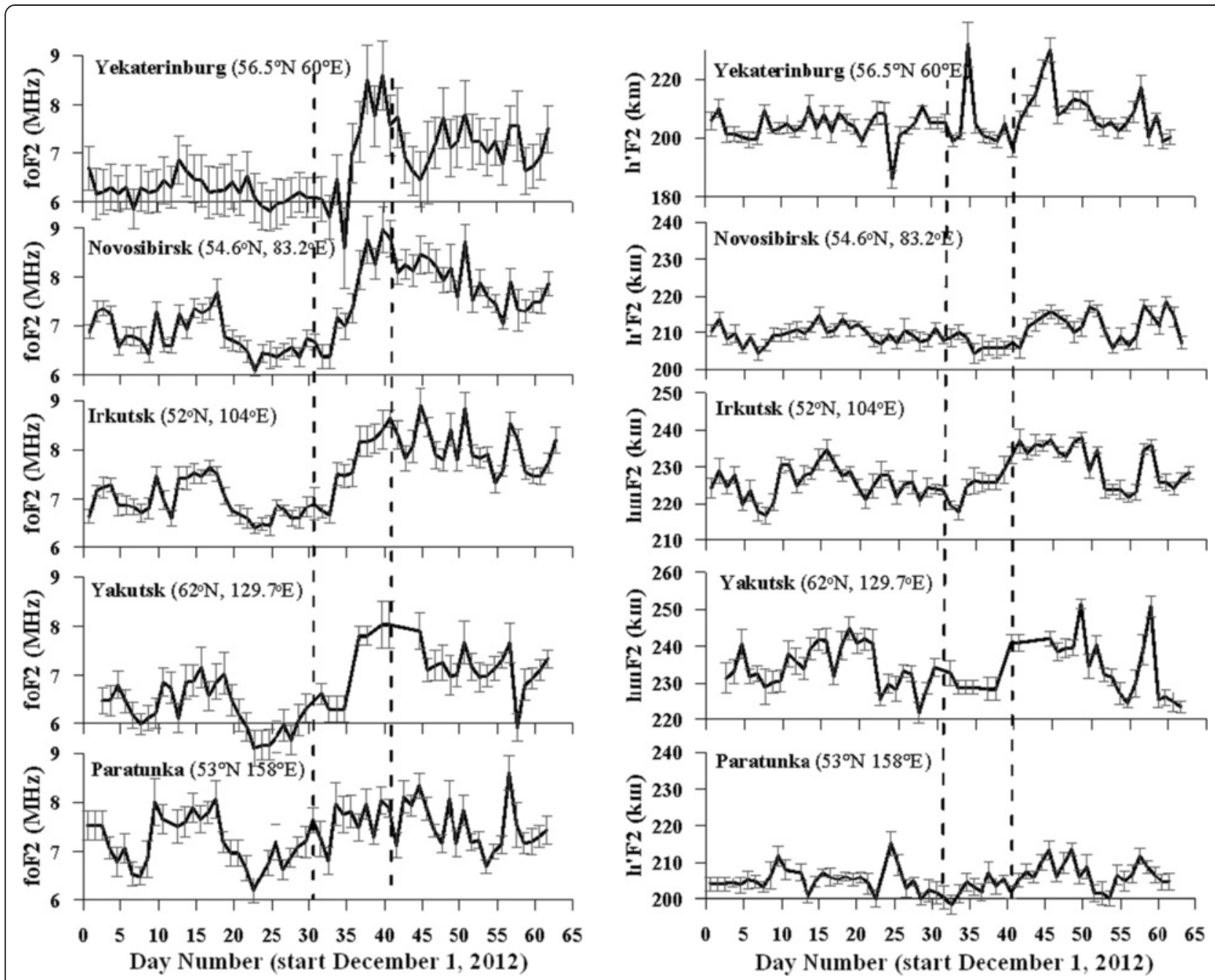

Figure 7 Variations of the averaged daytime $f_{o} F 2$ and $h_{m} F 2$ from five high-midlatitude Russian ionosondes for SSW 2012 to 2013.

positive response (at 50 to $60 \mathrm{~km}$ ) in Yakutsk during the 6-day period; no clear response was shown in Paratunka. Such abrupt longitudinal irregularity of the ionosphere in midlatitudes during quiet geomagnetic conditions was unexpected and may be explained only by the dynamics of the neutral atmosphere below. We used a classical approach (Rishbeth 1998) for explanation of ionospheric variations by changing the molecular gas density in the lower thermosphere. In diffusion equilibrium conditions, if some process transports molecular gas to the lower thermosphere, it then results in a decrease in $\mathrm{f}_{\mathrm{o}} \mathrm{F} 2$ and an increase in $\mathrm{h}_{\mathrm{m}} \mathrm{F} 2$. If the molecular gas density in the lower thermosphere decreases, the reverse is true.

The left bottom panel in Figure 2 shows that highest variations of ionospheric parameters appear above the region in which stratospheric cyclones and anticyclones collide and move poleward together. This active region is usually a zone of stratospheric heating and can likely generate internal gravity waves (IGW) that can propagate to higher altitudes. The IGWs can induce vertical transport of atmospheric constituents in the mesosphere and lower thermosphere region (e.g., Gardner and Liu 2010) and may have fountain effects that include movement of molecular gas to the lower thermosphere. However, the local increase in $\mathrm{h}_{\mathrm{m}} \mathrm{F} 2$ by 50 to $60 \mathrm{~km}$ in Yakutsk during the 6 -day period is an excessively large effect to be explained by influence of IGW activity.

Moreover, a relatively short decrease in $\mathrm{h}_{\mathrm{m}} \mathrm{F} 2$ both in day (Figure 5) and night (Figure 6) was observed over the center of the stratospheric cyclone in Yekaterinburg and Novosibirsk and partially in Irkutsk (days 53 to 55) when an increase in $h_{m} F 2$ was observed in Yakutsk. Classical works (e.g., Gill 1982) show that the lowpressure region in the center of an atmospheric cyclone involves molecular particles of circulation from the center to the jet stream. Atomic oxygen and nitrogen in the lower ionosphere do not participate in this 

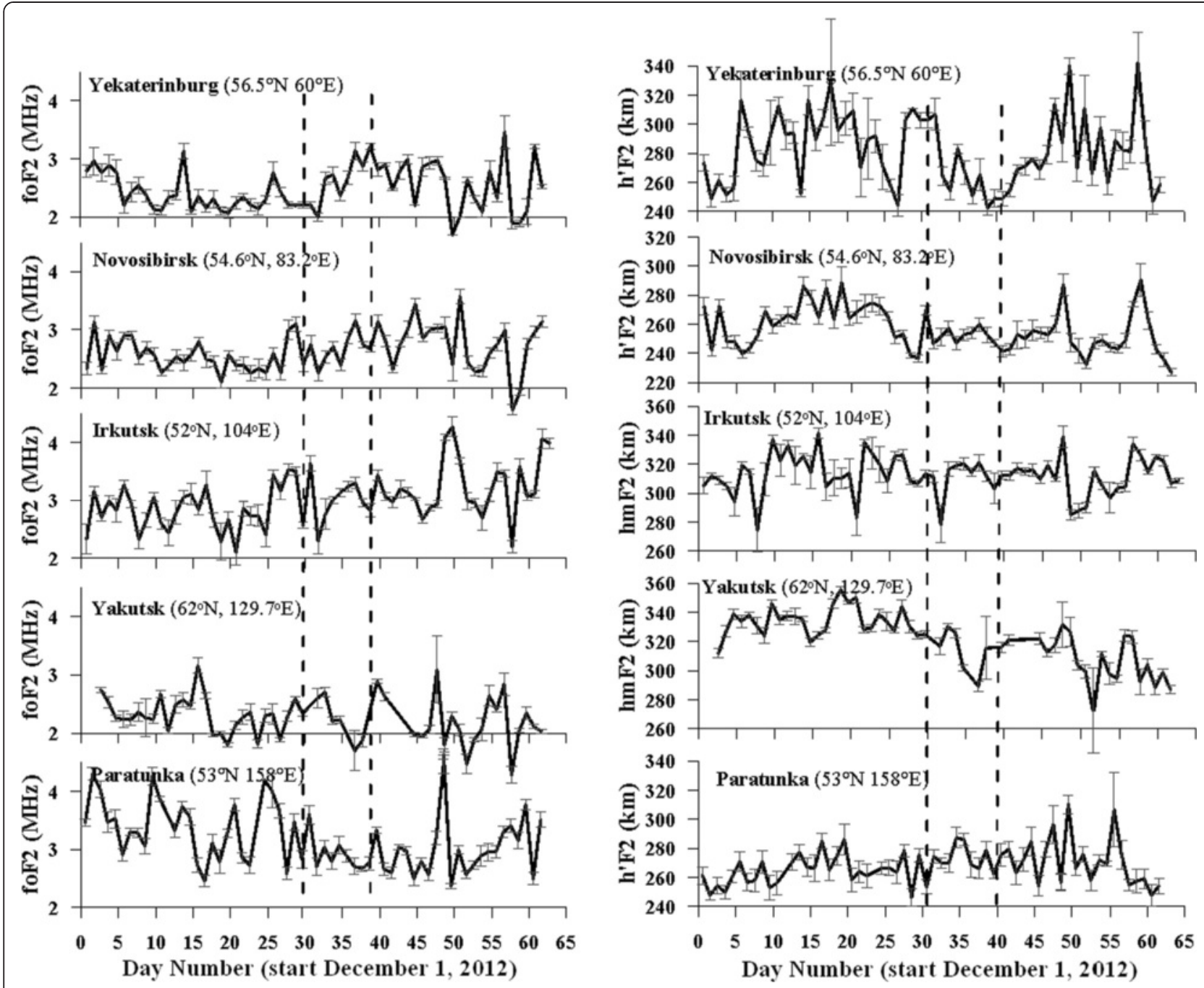

Figure 8 Same as Figure 7 but for averaged nighttime variations.

volumetric process due to the absence of molecular viscosity. Hence, pulldown forcing occurs above the center of a stratospheric cyclone. This process decreases the density of the molecular species in the mesosphere and lower thermosphere, which results in a decrease in $h_{m} F 2$ and an increase in $f_{o} F 2$. Because the positions of stratospheric circulation patterns change slightly from day to night, the Irkutsk ionosonde shows day-to-day variations that correlate at different times with those of Yakutsk and Novosibirsk.

The response of ionosphere over Russia to the major SSW 2012/2013

The SSW in December 2012 to January 2013 developed during a higher solar activity period than that of SSW 2008 to 2009. As shown in Figure 4, the geomagnetic activity during this event was quiet. The summary Kp did not exceed 25 during the event, and the solar activity index showed an increase in solar flux from approximately 100 to approximately 160 observed by all ionosondes as a gradual increase in $\mathrm{f}_{\mathrm{o}} \mathrm{F} 2$ in the daytime.

SSW 2012 to 2013 appeared as a significant shift of the circumpolar vortex from the northern pole that created the two-vortex structure (Figure 2). Figures 7 and 8 present day-to-day variations of the ionosphere parameters in the same manner as those in Figures 5 and 6.

During the main phase of this event ( 1 to 9 January), a cyclonic cell formed over Yekaterinburg. Variations of daytime $\mathrm{f}_{\mathrm{o}} \mathrm{F} 2$ at this site were largest of all ionosondes in this study (Figure 7). On 4 January, a sharp decrease in $\mathrm{f}_{\mathrm{o}} \mathrm{F} 2$ (approximately $1 \mathrm{MHz}$ ) and an increase in $\mathrm{h}_{\mathrm{m}} \mathrm{F} 2$ (approximately $30 \mathrm{~km}$ ) occurred that were not observed at the other stations. Subsequently, an increase of more than approximately $2 \mathrm{MHz} \mathrm{f}_{\mathrm{o}} \mathrm{F} 2$ was observed during a 3 -day period with an insignificant decrease in $h_{m} F 2$. The effects of daytime $f_{o} F 2$ increases and small $h_{m} F 2$ 
decreases were observed in all sites except Paratunka. Variations of nighttime $\mathrm{f}_{\mathrm{o}} \mathrm{F} 2$ (Figure 8 ) were positive in Yekaterinburg, Novosibirsk, and Irkutsk and negative in Yakutsk and Paratunka. Moreover, the decrease in nighttime $h_{m} F 2$ observed in Yakutsk with simultaneous lowering of $\mathrm{f}_{\mathrm{o}} \mathrm{F} 2$ was highly unusual.

The growth of $\mathrm{f}_{\mathrm{o}} \mathrm{F} 2$ in the SSW 2012 to 2013 event in particular can be attributed to increases in solar radiance during this period, which is evident in F10.7 index variations (Figure 4). However, this effect must be the same for all sites. More reasonable explanation of uneven longitudinal structure of the ionosphere can be determined from analysis of the atmosphere pressure distribution, which can be estimated from UKMO geopotential height data. Figure 9 shows variations of $10 \mathrm{hPa}$ pressure level heights, hereinafter referred to as $10 \mathrm{hPa}$ height (in meters), along $55^{\circ} \mathrm{N}$ latitude. A zero value corresponds to undisturbed height at approximately $31 \mathrm{~km}$. Large (low) $10 \mathrm{hPa}$ height indicates a low-pressure (high-pressure) area representing a stratospheric cyclone (anticyclone). Plots in the figure shows $10 \mathrm{hPa}$ height for 30 December (blue line) just before the SSW event, 3 January (red line) during the event, and 20 January (black line) during relatively normal conditions. Additional dashed lines in the figure represent longitudes of ionosondes.

We suggest that the altitude distribution of molecular gas is exponential and that spatial variation of pressure in the stratosphere produces similar spatial variation in the mesosphere and lower thermosphere. It is obvious that the Yekaterinburg site has favorable conditions for involving molecular species from the lower thermosphere, which leads increases in $\mathrm{f}_{\mathrm{o}} \mathrm{F} 2$. This effect was weaker at Novosibirsk, Irkutsk, and Yakutsk and minimal at Paratunka. Variations observed during SSW 2012 to 2013 may be the combined effect of F10.7 increase and CPV division. Increases in solar radiation flux effects generally appear at daytime; neutral atmosphere circulation only modulates this process on latitudes. At nighttime, dynamics similar to those observed during SSW 2008 to 2009 occur with positive (negative) $\mathrm{f}_{\mathrm{o}} \mathrm{F} 2$ effects above the cyclone (high-pressure zone) at Yekaterinburg (Yakutsk and Paratunka).

\section{Discussion}

The two SSW events occurring in winters of 2008 to 2009 and 2012 to 2013 are powerful events that were registered in epochs of well-developed instrumental observations of the middle atmosphere and ionosphere. These phenomena allowed for joint analyses of neutral atmosphere and ionosphere parameters. However, satellite data for ionosphere parameters such as FORMOSAT-3/ COSMIC data cannot replace ionosonde chain data when the investigated phenomena require good spatial resolution. When preparing experimental data for this study, we attempted to obtain ionosonde data from American/Canadian sectors and we were surprised by the absence of high-midlatitude stations in these regions. For the present study, the fact that some observatories use old-generation equipment was unimportant; rather, the

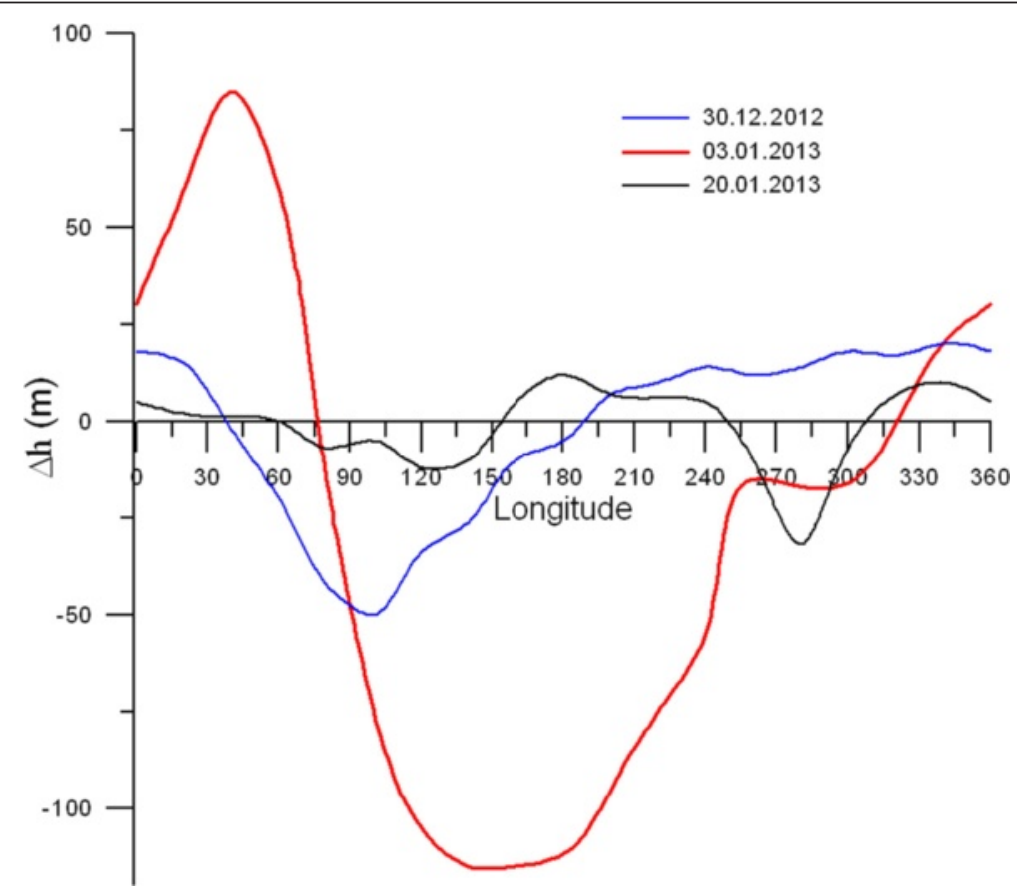

Figure 9 Variations of $10-\mathrm{hPa}$ pressure level heights along $55^{\circ} \mathrm{N}$ latitude. Dashed lines represent longitudes of ionosondes. 
critical factor was that the Russian ionosonde chain is continuous.

The main conclusion of the present study is an obvious dependence between stratospheric circulation structures and ionosphere dynamics. The midlatitude ionosphere in winter may be affected by large-scale stratospheric processes, and its longitudinal structure may be significantly uneven during a period of several days.

From the results of the present study, we were unable to definitively determine the stratosphere-mesosphereionosphere transport processes responsible for the observed ionosphere-neutral atmosphere coupling. To make a definite conclusion, analysis of the mesosphere data on vertical drift and IGWs is required.

The effect of $\mathrm{f}_{\mathrm{o}} \mathrm{F} 2$ increases above the center of a cyclone can be explained by pulldown forcing, which is in agreement with classical theory of atmospheric dynamics. However, the effects of local enhancement of $h_{m} F 2$ in Yakutsk for a few days during SSW 2008 to 2009 differed significantly from usual ionospheric variations observed in other atmospheric and geomagnetic conditions. If the effects are similar to the fountain effect, the mechanism for its explanation should be determined. If the effects are similar to those of IGW forcing, it is necessary to explain why these waves are highly localized and do not propagate to other latitudes or longitudes, which is usually observed in ionospheric experiments.

In any case, the results of this study require additional investigations of SSW phenomena involving new experimental data on the stratosphere, mesosphere, and lower thermosphere. The latitudinal chain of ionosondes can be also extended by including European ionosonde stations.

\section{Competing interests}

The authors declare that they have no competing interests.

\section{Authors' contributions}

BS carried out the joint ionosonde data processing and drafted the manuscript. DP and PM provided UKMO data processing and helped draft the manuscript. VK organized the coordinated observation on ionosonde chain and helped draft the manuscript. MC was responsible for NCEP/NCAR Reanalysis data presentation. The ionosonde chain team provided data from SG - Yekaterinburg; AB - Novosibirsk; KR - Irkutsk, Norilsk; AS - Yakutsk; and VB - Paratunka. All authors read and approved the final manuscript.

\section{Acknowledgements}

The work was conducted in the frame of the joint Russian-Bulgarian project 'Atmosphere-lonosphere Coupling during Sudden Stratospheric Warming.' This work was supported by Russian Foundation for Basic Research (Grants RFBR No. 13-05-00292 and 14-05-00259). We are grateful to the UKMO and the BADC for providing access to the data on http://www.badc.rl.ac.uk/data/ assim. We also thank E. Sutyrina for providing a graphical presentation of NCEP/NCAR reanalysis data.

\section{Author details}

${ }^{1}$ Institute of Solar-Terrestrial Physics SB RAS, Irkutsk, Russia. ${ }^{2}$ Geophysical Survey SB RAS, Altay-Sayan Department, Novosibirsk, Russia. ${ }^{3}$ Institute of Geophysics UB RAS, Yekaterinburg, Russia. ${ }^{4}$ Institute of Cosmophysical Research and Aeronomy SB RAS, Yakutsk, Russia. ${ }^{5}$ Institute of Cosmophysical Researches and Radio Wave Propagation EB RAS, Paratunka, Russia. ${ }^{6}$ National Institute of Geophysics, Geodesy and Geography, Sofia, Bulgaria.
Received: 28 April 2014 Accepted: 15 January 2015

Published online: 11 February 2015

\section{References}

Chau JL, Fejer BG, Goncharenko LP (2009) Quiet variability of equatorial ExB drifts during sudden stratospheric warming event. Geophys Res Lett 36:L05101, doi:10.1029/2008GL036785

Gardner CS, Liu AZ (2010) Wave-induced transport of atmospheric constituents and its effect on the mesospheric Na layer. J Geophys Res 115:D20302, doi:10.1029/2010JD014140

Gill AE (1982) Atmosphere-Ocean Dynamics. Academic Press, London, International Geophysics Series 30: 680

Goncharenko L, A Coster, J Chau and C Valladares (2010a). Impact of sudden stratospheric warmings on equatorial ionization anomaly. J. Geophys. Res. 115, A00G07, doi:10.1029/2010JA015400.

Goncharenko LP, Chau JL, Liu H-L, Coster AJ (2010b), Unexpected connections between the stratosphere and ionosphere. Geophys Res Lett 37, L10101, doi:10.1029/2010GL043125.

Liu H-L, Roble RG (2002) A study of a self-generated stratospheric sudden warming and its mesospheric-lower thermospheric impacts using the coupled TIME-GCM/CCM3. J Geophys Res 107(D23):4695, doi:10.1029/2001JD001533

Pancheva D, Mukhtarov P (2011) Stratospheric warmings: the atmosphere-ionosphere coupling paradigm. J Atmos Sol-Terr Phys 73:1697-1702, doi:10.1016/j. jastp.2011.03.066

Rishbeth H (1998) How the thermospheric circulation affects the ionospheric F2 layer. JASTP 60:1385-1402

Saha S, S Moorthi, X Wu, J Wang, S Nadiga, P Tripp, D Behringer, Y-T Hou, H-Y Chuang, M Iredell, M Ek, J Meng, R Yang, M Pena, H van den Dool, Q Zhang, W Wang, M Chen, E Becker, (2013). The NCEP Climate Forecast System Version 2. J. Climate;P. 130925135638001. doi:10.1175/JCLI-D-12-00823.1.

Swinbank R, Ortland DA (2003) Compilation of the wind data for the Upper Atmosphere Research Satellite (UARS) Reference Atmosphere Project. J Geophys Res 108(D19):4615, doi:10.1029/ 2002JD003135

\section{Submit your manuscript to a SpringerOpen ${ }^{\mathcal{D}}$ journal and benefit from:}

- Convenient online submission

- Rigorous peer review

- Immediate publication on acceptance

- Open access: articles freely available online

- High visibility within the field

- Retaining the copyright to your article

Submit your next manuscript at springeropen.com 